\title{
Rodrigo Parrini. «Deseografías. Una antropología del deseo» Apuntes desde el oficio del etnógrafo. México, Universidad Autónoma Metropolitana, 2018, 504 págs.
}

\section{CARLA PINOCHET*}

«Deseografías. Una antropología del deseo» es un libro que se despliega, en cada una de sus secciones, en diversas direcciones y sentidos. Es difícil escoger un solo ángulo para dar cuenta de las líneas que se proyectan en este ejercicio, y es quizás la propia naturaleza de su objeto de estudio la que le impone esta vocación múltiple, compleja y simultánea. Una antropología del deseo parece un proyecto esquivo, al que Rodrigo se enfrenta desde una batería de recursos interdisciplinarios que cautivan y sumergen al lector en un particular cronotopo: sus años de experiencia etnográfica en torno al Club Gay Amazonas, en la localidad de Tenosique, frontera sur de México. La productiva y persistente conciencia con la que Rodrigo trabaja ese lugar de enunciación, me invita también a señalar mis propias coordenadas de lectura de la obra, que refieren sobre todo a un domicilio disciplinar: el oficio de la etnografía. En este texto, entonces, quisiera elaborar algunos apuntes que examinan el libro en tanto modo de acomodar la empresa antropológica a sus propios ritmos y tesituras, reorganizando sus sentidos y sus efectos en la escritura de un caso que, aunque singular, permite a Rodrigo multiplicar el análisis hacia adentro develando sus posibilidades infinitas. Si las Deseografías que aquí se nos proponen nos confrontan con el problema de la inscripción, intentaré en estas líneas ofrecer una suerte de mapa que permita cartografiar las muchas razones por las que este libro constituye una notable contribución al desarrollo de una etnografía contemporánea.
A través de un fluido contrapunto entre el trabajo de campo y la discusión conceptual, el libro que aquí presentamos explora las tramas discursivas y de sociabilidad que se tejen alrededor del Club Amazonas, institución flexible y móvil que da forma a la colectividad gay de Tenosique, y hace posible su constitución como interlocutor legítimo en la localidad. Pero no se trata solamente de la historia de estas batallas institucionales en una arena política hostil: "Deseografías», en su ambiciosa búsqueda de acceder a aquel "sustrato de piedra" que subyace a los sujetos, tiende puentes entre la descripción de las formaciones colectivas y los procesos biográficos de quienes las conforman. En este sentido, este texto entrega un sugerente modo de responder a una de las interrogantes basales del ejercicio etnográfico: la tensión entre lo individual y lo social. La inscripción del deseo, de esta forma, no es solo un acontecimiento subjetivo: hay modos de practicarlo que se muestran transversales; hay formas de hablar de él que resultan convergentes. La doble formación de su autor en psicología y antropología encuentra un canal de expresión en la pregunta por el «entre»: el deseo no reside en las personas sino que habita entre ellos, siempre como una forma de intercambio, como una economía. Es preciso pensarlo, señala el autor, "como una intensidad que desmiente la distinción entre intimidad y exterioridad, entre dentro y fuera, entre sujeto y colectivo, entre orden psíquico y orden social” (p. 21).

* Dra. en Ciencias Antropológicas. Académica Departamento de Antropología, Universidad Alberto Hurtado. Santiago de Chile. Correo-e: cpinochet@uahurtado.cl 
El libro, por otra parte, identifica en los sujetos de su estudio un terreno privilegiado para actualizar algunas de las atávicas obsesiones de la antropología: la pregunta por el otro, y específicamente, por las figuras que se sitúan en los márgenes del orden social e incluso de la propia condición humana. Las diversas representaciones del homosexual que coexisten en la localidad lo sitúan próximos a la depravación, la indecencia o la inmoralidad. A la vez, estos discursos resuelven de modos particulares el dilema de su expresión híbrida: como las prohibiciones del Levítico de las que hablara Mary Douglas -que proscriben aquello que resulta inclasificable - estos hombres y mujeres a la vez responden a una pluralidad de subjetividades que perturba los esquemas locales. En este marco, el libro ofrece un relato del proceso mediante el cual devienen sujetos políticos, que no es sino también una forma de humanización; al mismo tiempo, documenta los modos en que diversas fuerzas sociales buscan confinar, administrar y regular esos cuerpos para darles un tiempo y espacio que los haga admisibles, tolerables, imaginables.

Las epistemes locales que describe Rodrigo dan cuenta de los usos heterodoxos que los actores hacen de diversos repertorios discursivos en torno a la homosexualidad y el deseo gay, introduciéndose en las profundidades del lenguaje en tanto forma de organizar el mundo. Esta atención al problema de las categorías tiene una vasta genealogía en la tradición antropológica, largamente desvelada ante la arbitrariedad del signo y del orden social. Haciendo eco de las heterotopías convocadas por Foucault, nos enfrentamos a la evidencia de los "órdenes que no son los únicos ni los mejores", y que adquieren su espesor particular en la convivencia desnivelada — no exenta de fricciones- con otros órdenes posibles. Putos, homosexuales y gays aparecen, entonces, como registros disonantes que se superponen, colisionan y se complementan en la topografía conceptual de Tenosique.

Sin embargo, aun cuando los esquemas conceptuales nos permiten pensar, nos dice el autor que "no necesariamente resuelven la práctica ni la determinan cabalmente" (p. 156). Por ello es preciso saltar del plano discursivo hacia la dimensión de las prácticas, o más específicamente, comprender las disposiciones complejas en que ambos niveles interactúan en el campo social. En una revisión crítica de los supuestos del giro textual en antropología —que imagina la operación etnográfica como la lectura de un manuscrito extranjero, borroso, lleno de elipsis y enmiendas-, Parrini pone atención a los momentos en que una conducta se transforma en acción simbólica. Se aproxima así a los modos en que las formas discursivas se inscriben en los cuerpos, habilitando estilos de vida y formas de sociabilidad. En específico, ofrece una entrada a las prácticas de sí que hacen posible la configuración del sujeto homosexual a partir o alrededor de su deseo. Estas homoprácticas constituyen una bisagra entre subjetividad y sociabilidad; entre relatos identitarios y modos de desplegar la conducta: darse un nombre, respetarse, conocerse a sí mismo, relevar las características positivas asociadas a la homosexualidad. Para que todo ello tuviera lugar en Tenosique, fue preciso que el deseo se convirtiera en ambiente, y el ambiente en esfera. El Club Amazonas ofreció, entonces, un círculo de protección a la hora del despliegue de esas subjetividades deseantes. "¿No es el Club un "abrigo" que los hombres gays "arrojaron sobre sí mismos" para sobrevivir a la enfermedad y la muerte?", se pregunta el autor (p. 206). 
Hay en el libro, además, un empeño por ocuparse de otra de las grandes tensiones que sirven de motor a la antropología: la de lo estable y lo emergente. Merodeando la colosal pregunta planteada por Deleuze «¿cómo es posible la producción de algo nuevo en el mundo?», el libro muestra menos interés por las identidades consolidadas que por aquello que se encuentra en permanente permutación. Lo provisional tendrá, por lo tanto, un lugar privilegiado en el relato: los intercambios, las oscilaciones, las posiciones intercambiables. Por una parte, devela las sucesivas operaciones de conversión entre lo genético y lo biográfico; entre lo sanitario y lo moral; entre las verdades médicas y las sociológicas; así como las intrincadas maneras en que estos tránsitos configuran una economía libidinal en y entre los cuerpos. Por la otra, examina con especial atención los fenómenos contemporáneos que, en el contexto de las formas de vida de Tenosique, refieren al movimiento: los desplazamientos poblacionales -militares, migrantes, crimen organizado-que impactan en este paraje fronterizo; la metálica presencia de un tren-bestia que pone en crisis las formas convencionales de la soberanía. La idea de «flujo» aparece aquí como una llave analítica indispensable para aprehender estos escenarios móviles, amparándose en la noción de «diferencia»: el movimiento de los elementos de un punto a otro permite pensar registros distintos. El deseo se observa, en primera instancia, como "un flujo entre diferencias eróticas, corporales, sexuales, subjetivas y sociales", pero también, en un nivel segundo, "como una diferencia entre colectivos, comunidades y sociedades" (p. 315).

Para una antropología contemporánea, el libro de Rodrigo resulta también ejemplar en su manera de resolver las brechas entre lo local y lo global. Ante la potencia de estos influjos, el texto se pregunta por las herramientas que dispone la localidad para determinar su destino avasallado por estos tiempos álgidos, y los modos en que estos efectos retumban en la "apretada red de enlaces y pláticas intensamente locales, barriales, familiares" que caracteriza a Tenosique. Rodrigo escoge seguir la ruta de las «fricciones» que situarán a la localidad en la encrucijada de los flujos migratorios y criminales de la región, entendiendo cómo estas fuerzas globales se materializan y condensan en sujetos y objetos concretos. Esta apuesta por las fricciones empalma además con el papel que el autor entrega a los «antagonismos» como detonadores de la descripción cualitativa: en lo que entiende como una «etnografía lateral», capaz de abordar conexiones parciales pero no por ello menos complejas, el autor opta por introducirse en el análisis allí donde diversas prácticas y esquemas mentales entran en conflicto, es decir, donde el mundo social expresa sus más claras superficies de rozamiento.

He querido señalar algunos niveles en los que «Deseografías» se hace cargo de los grandes dilemas de la práctica etnográfica: lo individual y lo social; las categorías y lo inclasificable; los discursos y las prácticas; lo estable y lo provisorio; lo local y lo global; el lugar del conflicto y el antagonismo. Pero tal vez el ámbito donde su filiación con la antropología resulta más productiva es en el despliegue de una escritura luminosa, que guía metódicamente al lector por los laberintos intrincados del deseo. Heredera de la reflexividad y autoconsciencia que ha caracterizado buena parte de la producción de textos etnográficos contemporáneos, este libro no puede sino adoptar la primera persona singular para dar cuenta del lugar profunda- 
mente situado, subjetivo y personal desde el que su autor teje este relato. Haciendo gala de un singular control dramático —un relato impresionista, diría Van Maanen en su libro sobre escritura etnográfica-, el libro de Rodrigo Parrini restituye el lugar de la sensibilidad en la descripción antropológica, permitiendo vislumbrar modos del análisis que no destruyen; formas de conocer que no anudan. En este espléndido paisaje literario, «Deseografías» despliega un ejército de metáforas, comparaciones y analogías que demuestran que re-nombrar es una forma de capturar lo huidizo y hacerlo pensable. El ejercicio metafórico, como demuestra este libro, es consustancial a la imaginación antropológica, y lo que sabemos del Club Gay Amazonas después de leerlo ya no puede explicarse sin la idea de «fármaco»: a la vez veneno y medicina, el Club en tanto fármaco ha operado como un sistema inmune colectivo para sus integrantes, protegiéndolos de la enfermedad y del abandono al habilitar un lugar social para su deseo.

En suma, «Deseografías. Una antropología del deseo» pone de relieve de forma asertiva muchos de los nodos críticos en los que, a mi juicio, se juega hoy en día el ejercicio de una etnografía contemporánea, capaz de proyectar las interrogantes tradicionales de dicha disciplina a las múltiples puestas en crisis que le imprimen los tiempos actuales. Esperando que, efectivamente, este sea el primer volumen de muchos otros, no me queda más que celebrar la aparición de estas Deseografías como algo nuevo en el mundo, y alentar a todos los que están aquí presentes a asistir a este nacimiento extraordinario.

\section{Carla Pinochet Cobos} Universidad Alberto Hurtado 